Full length Article

\title{
Techno-economic assessment of bioethanol production from lignocellulose by consortium-based consolidated bioprocessing at industrial scale
}

\author{
David Dempfle ${ }^{\mathrm{a}, \mathrm{b}}$, Oliver Kröcher ${ }^{\mathrm{a}, \mathrm{c}}$, Michael Hans-Peter Studer ${ }^{\mathrm{b}, *}$ \\ ${ }^{a}$ Group of Catalysis for Biofuels, Institute of Chemical Science and Engineering, École Polytechnique Fédérale de Lausanne (EPFL), 1015 Lausanne, Switzerland \\ ${ }^{\mathrm{b}}$ Laboratory of Biofuels and Biochemicals, School of Agricultural, Forest and Food Sciences, Bern University of Applied Sciences (BFH), 3052 Zollikofen, Switzerland \\ ${ }^{\mathrm{c}}$ Paul Scherrer Institut (PSI), 5232 Villigen, Switzerland
}

\section{A R T I C L E I N F O}

\section{Keywords:}

Biofuels

Ethanol

Lignocellulose

Consolidated bioprocessing

Techno-economic assessment

\begin{abstract}
A B S T R A C T
Lignocellulose-based biofuels are of major importance to mitigate the impact of international traffic and transport on climate change while sustaining agricultural land for food supply. Highly integrated systems like consolidated bioprocessing (CBP), where enzyme production, enzymatic hydrolysis and fermentation of the released sugars are carried out in one reactor, offer the highest potential to save costs and to make lignocellulosebased biofuels economically competitive. The work described here showed that CBP based on a microbial consortium operated at full-scale $(2000 \mathrm{t} / \mathrm{d})$ saves up to $27.5 \%$ of the total ethanol production costs compared to conventional ethanol production from lignocellulose in individual process steps. The cost savings are mainly achieved through lower CAPEX due to less apparatus requirements because of the integrated process, as well as through lower OPEX since no glucose is needed for enzyme production. A comparison with literature estimations of cost savings of CBP based on genetically modified microorganisms results in approximately the same range. As a result of a detailed sensitivity analysis, scale and yield were identified as the main cost-pushers from a process point of view, whereas the price level of the plant location has the highest impact on the investment conditions. In the EU, CBP yields enough margin for profitable production and the possibility to decentralize biomass valorization, whereas in the world's largest ethanol market, the U.S, profitable production of lignocellulosic ethanol can only be achieved by CBP combined with other cost saving techniques, such as utilization of cost-free waste feedstocks, since ethanol has undergone a considerable price slump.
\end{abstract}

\section{Introduction}

According to the international energy outlook 2020 of the US Energy Information Administration, the world's energy consumption for transportation will continue to increase at an average annual rate of 1.3 $\pm 0.2 \%$, leading to a projected total consumption of roughly 290 Exajoule (EJ) in 2050, which is mainly driven by a doubled energy demand in non-OECD countries in 2050 compared to 2018 [1]. The expected share of electrical power supply in the light duty transportation sector will not exceed $30 \%$ until 2050 and will remain negligible in the heavy duty transportation sector $(<1 \%$ in 2040) due to several drawbacks such as low energy density and limited storage possibilities [2-4]. If these 290 EJ were to be provided by fossil fuels, the average world temperature would increase by about $6{ }^{\circ} \mathrm{C}$, or $4{ }^{\circ} \mathrm{C}$ above the limit of the Paris agreement reached by the UN Framework Convention on Climate Change in 2015 [5]. Models based on the $2{ }^{\circ} \mathrm{C}$ International Energy Agency Technology Perspective claim that 12, 25 and $38 \%$ of the world's transportation energy must be provided by liquid biofuels in 2030, 2050 and 2075, respectively [3,6].

As the predominant liquid biofuel, bioethanol plays a major role as reactant for heavy duty transport fuel additives or as fuel for adapted light duty vehicles $[7,8]$. However, currently bioethanol is produced

Abbreviations: AFEX, ammonia fiber expansion; CAPEX, capital expenditures; CBP, consolidated bioprocesses; CCR, capital charge rate; CEPCI, chemical engi-

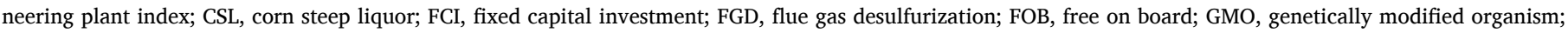

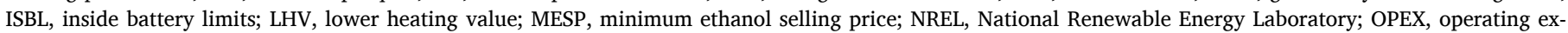

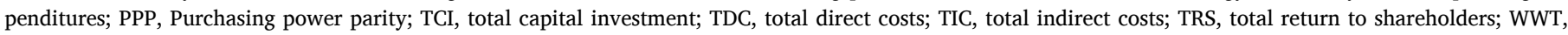
wastewater treatment.

* Corresponding author.

E-mail address: michael.studer1@bfh.ch (M.H.-P. Studer). 
mainly from edible feedstocks (share $>96 \%$ ) [9]. These so-called first generation biofuels not only cause a conflict between fuel supply and food/feed issues, but they may have a non-compensable carbon footprint [10]. Lignocellulosic biomass, the most abundant resource of fixed renewable carbon in the world, serves as feedstock for second generation biofuels having a much lower or even no carbon debt compared to first generation biofuels and the conflict with the feed and food industry is avoided since it is non-edible $[10,11]$. The production of lignocellulosic ethanol gained attraction in the context of the "bio-based economy" vision and has been in growth on an industrial scale since the early 2000s [12,13]. Policy makers aim to further incentivize the use of lignocellulose, as was done by the US government with the "Second generation biofuel producer tax credit", which expires by the end of 2021 [14]. The EU set a target of a $3.5 \%$ share of second generation biofuels in the transport sector by 2030 with an intermediate milestone of a 1\% share in 2025 in the framework of the Renewable Energy Directive II [9].

State-of-the-art lignocellulosic bioethanol production is carried out in the following process steps (Fig. 1a). The raw feedstock is pretreated mechanically (e.g. chipping) to reduce the particle size and physiochemically (e.g. steam pretreatment or dilute acid pretreatment) to break up the entanglement between cellulose, hemicellulose and lignin and to make the poly-sugars accessible to enzymes $[11,15]$. The facilitated accessibility of the cellulose fibers increases the yield and rate of hydrolysis by a factor of 3-10 [16]. The pretreated biomass is conditioned to adjust $\mathrm{pH}$ and temperature for enzymatic hydrolysis. A washing step to reduce the concentration of inhibitors formed during the pretreatment is not mandatory since the abilities of white rot fungi to detoxify the fermentation broth are well-known [17]. The hydrolytic enzymes are either produced in a separate aerobic fed-batch culture or purchased from an external vendor. The sugars released by enzymatic hydrolysis are fermented in a subsequent step. Finally, the solids and the major part of the water is removed in a first distillation column (beer tower) and anhydrous ethanol is obtained from rectification in a second distillation column usually followed by dehydration using molecular sieves. Lignocellulosic bioethanol is currently more expensive than ethanol from sugar crops or corn despite the cheaper raw material price per unit mass of feedstock. This is due to (i) lower concentration of carbohydrates in the feedstock leading to lower final ethanol concentrations, (ii) lower conversion rates of lignocellulosic feedstocks leading to larger vessels and with that higher capital costs and (iii) the necessity of an elaborate pretreatment $[11,12,18,19]$.

In 2008 , the hypothesis was proposed that lignocellulosic ethanol will become cheaper than ethanol produced from corn or sugar crops as a result of improved technology due to maturing of the process [19]. Improvements by integration of several process steps were identified as the strongest levers to reduce processing costs, which is not only true for biotechnology but for chemical engineering in general [20]. The highest degree of process integration for bio-ethanol production is achieved by consolidated bioprocessing (CBP), where enzymatic hydrolysis, enzyme production and fermentation are performed in a single process step (Fig. 1b).

The enzyme production and the fermentation can be carried out simultaneously either with a single culture of a genetically modified microorganism or with a community of industrial, microbial strains [21]. A single culture strategy (hereafter termed "GMO-based CBP") must employ a genetically modified microorganism, since no known natural strain is able to hydrolyze cellulosic substrates and to ferment the released sugars exclusively to the desired target product ethanol. In contrast, in a microbial community the task of hydrolysis and fermentation is divided and assigned to single strains, which are co-cultivated to act synergistically as consortium, with each community member having its own stable niche in the reactor [22,23]. Such a system (hereafter termed "consortium-based CBP") has been deployed by developing a suitable reactor design and co-cultivating a stable microbial community of a cellulolytic fungus and ethanolytic yeast [24]. Oxygen is fed through a membrane to the otherwise anaerobic reactor to introduce a stable oxygen gradient into the system, which provides an aerobic niche for the cellulolytic strain Trichoderma reesei. The fungus forms a biofilm on top of the membrane in the oxygen-enriched layer,
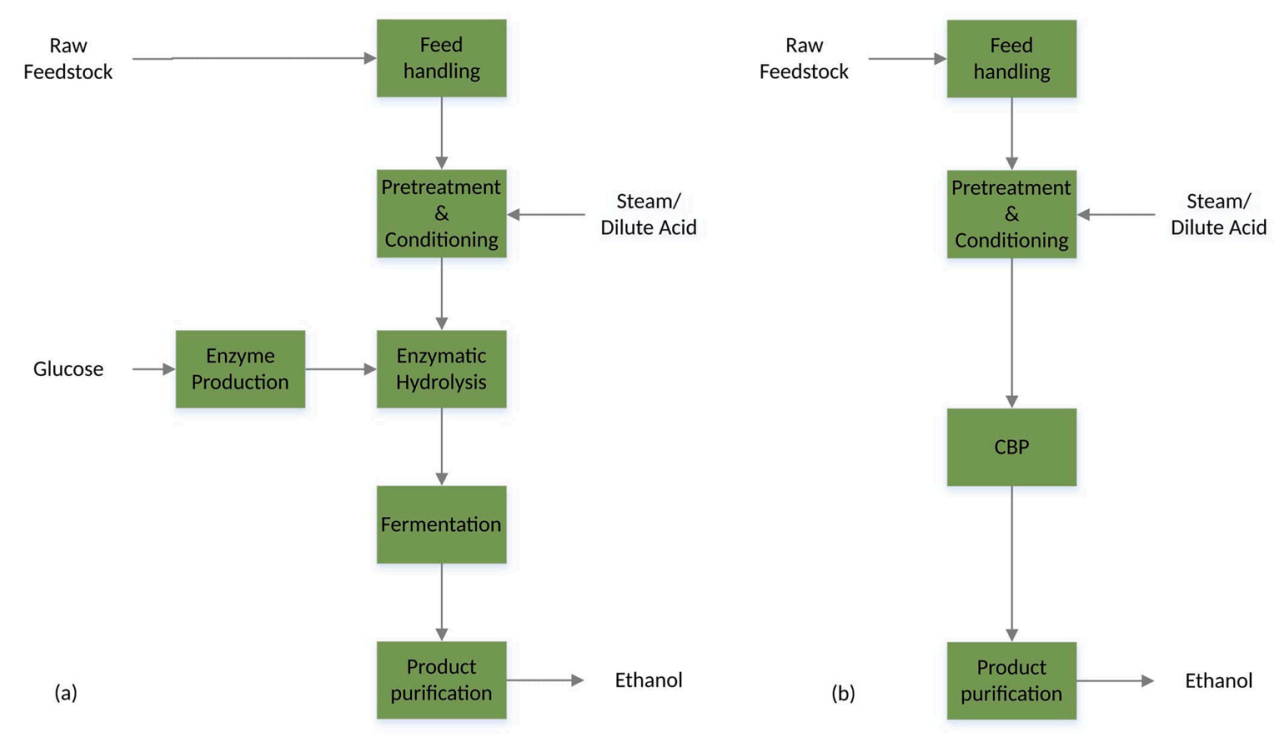

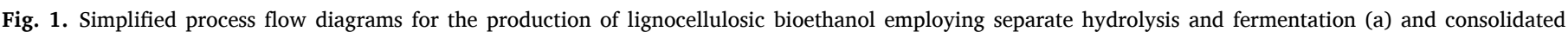

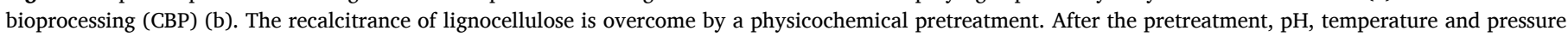

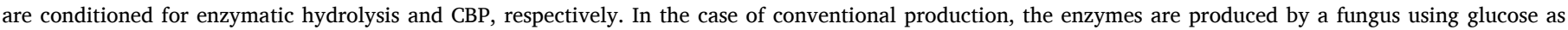

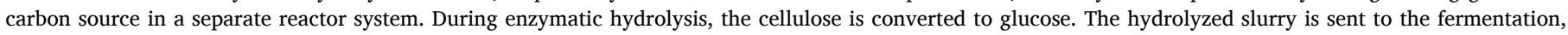

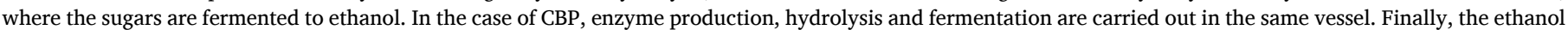
is recovered from the product stream by distillation and adsorption. 
while the fermenting strain, Saccharomyces cerevisiae, grows suspended in the anaerobic fermentation broth [24].

Considering a GMO-based CBP approach, cost savings of up to $41 \%$ of the processing costs of lignocellulosic ethanol have been reported [19]. However, imposed metabolic burden, cytosolic or periplasmic space limitations, competing biochemical reactions and toxic intermediates limit the implementation possibilities of GMOs and yield poor fermentation performance. Therefore, complex tasks are distributed in nature either within subcellular compartments or between different microorganisms [25]. In a microbial community designed for synergistic division of labor, where each species has its own well-designed niche and a very specific task, complex biotransformations can be carried out in a stable and robust manner [21,26, 27].

This work aims to investigate the cost savings of the consortiumbased CBP approach compared to conventional bioethanol production from lignocellulose (separate hydrolysis and fermentation) and to GMObased CBP. Furthermore, a sensitivity analysis of the profitability as a function of scale, feedstock price, yield, residence time, cost of capital and price level of the country is carried out to investigate the commercial potential of bioethanol production from lignocellulosic feedstocks via consortium-based CBP in the light of the current ethanol market situation.

\section{Materials and methods}

\section{Base case conventional bioethanol production from lignocellulose}

The most recent process design and economics of lignocellulose-toethanol conversion at a scale of 2000 dry tons per year throughput published by the National Renewable Energy Laboratory of the US Department of Energy (NREL) was used as base case for the technoeconomic analysis (hereafter referred to as "base case") [28]. A minimum ethanol-selling price (MESP) of $57 \mathbb{C} /$ annual $\mathrm{L}$ ethanol results from the total processing costs and the cost of capital per year apportioned to the annual production of ethanol. All cost data of the base case refer to 2007 and the US.

\section{Process parameters of the consortium-based CBP}

Feedstock properties, ethanol titer and yield were assumed to be the same as in the base case in order to calculate the net savings by using CBP. The pretreatment was changed to a pure steam pretreatment instead of a dilute acid-catalyzed steam pretreatment used in the base case, because previous studies have successfully shown that steampretreated lignocellulose can be converted by consortium-based CBP and the CBP parameters are based on the available experimentally derived data with steam gun pretreatment $[17,29,30]$. The necessary, specific membrane surface was set to $10 \mathrm{~m}^{2} / \mathrm{m}^{3}$ reactor volume. The temperature of the CBP unit was set to $28{ }^{\circ} \mathrm{C}$ in favor of enzyme production to maximize the enzyme concentration, since the temperature dependence of the activity per enzyme unit following the Arrhenius law is negligible in the temperature band where the cultivated microorganisms grow $\left(27-32{ }^{\circ} \mathrm{C}\right)[24,31]$.

\section{Cost estimations}

Apparatus costs were either taken from the base case, from the previous NREL report of 2002 or by using well-accepted cost functions from the literature [32-35]. Any calculations, mass and energy balances as well as adapting cost values, were performed with Microsoft Excel®.

Cost data for the same equipment at different scales were converted according to equation (1) with the help of a size exponent $n$ taken either from the base case or literature (see SI) [28,32-35]: $(\text { size equipment } i / \text { size equipment } j)^{n}=$ cost equipment $i /$ cost equipment $j$

Unless otherwise stated, all equipment sizes are directly proportional to the volumetric flow.

Installation factors were used to derive the installed costs, which include piping, armatures and sensors, from the equipment costs [28, 32-35]. The calculation of the capital expenditures (CAPEX) proceeding from the apparatus costs was done according to the base case. The operating expenditures (OPEX) were subdivided into variable and fixed OPEX. The variable OPEX denote the costs for the consumables (mainly chemicals) and the feedstock. The costs per unit of consumable or feedstock were assumed to be the same as in the base case. The fixed OPEX consist of labor cost, maintenance, property insurance and tax. The same labor costs per worker are assumed as in the base case. All other fixed OPEX scale linearly with CAPEX and were calculated with the new CAPEX data according to the base case.

All costs are expressed either in absolute terms (US \$) or in annual costs divided by the annual ethanol production ( $\mathbb{C}$ /annual $\mathrm{L}$ ethanol). The chemical engineering plant cost index (CEPCI) was used to convert cost data from different years. Comparisons with the base case were performed with a CEPCI from 2007, the reference year of the base case. The sensitivity analysis is based on a CEPCI from 2019 in order to discuss the results with respect to the current situation in the ethanol market. Apart from re-dimensioning the apparatus (equation 1), all cost calculations as well as the CEPCI are linear. Thus, the cost savings of each apparatus could also have been evaluated with the CEPCI of 2019. However, since single apparatus may differ strongly from the general cost trends, it was decided to retain the cost calculations for single apparatus as close as possible to the base case and convert the overall results, where single outliers are likely to be cancelled out, with the help of the CEPCI.

\section{Results and discussion}

Cost savings through consortium-based CBP with steam pretreatment

The process economics of ethanol production of lignocellulose reported by NREL serve as the base case to determine the saved costs by CBP (see process scheme in Fig. 1a) [28]. This section presents the cost savings of the different process steps, re-dimensioning of individual apparatus may be found in the Supplementary Material A. The throughput of 2000 dry tons of corn stover per day as feedstock, which are converted to 231 million $\mathrm{L}$ of ethanol per year was kept constant as the same yield range could be confirmed experimentally with CBP [24]. The costs for feedstock acquisition and handling were also kept constant. The pretreatment of the corn stover was changed from dilute acid-catalyzed steam pretreatment to pure steam pretreatment. This increased CAPEX, since the apparatus must withstand higher pressures necessary in a pure steam pretreatment. Variable OPEX are saved due to the substantially reduced need for chemicals (acid for the pretreatment and base for conditioning). Applying CBP through merging enzyme production, hydrolysis and fermentation in one process step saves CAPEX due to a reduced number of apparatus for hydrolysis and fermentation, as well as to the omission of the enzyme production unit. Variable OPEX are mainly saved by leaving off the use of glucose for enzyme production as the enzymes are produced in-situ consuming carbon from the feedstock. The cellulose-to-ethanol yield in the CBP case [24] was adjusted to $76 \%$ in order to be the same as in the base case. Despite the fact that even small changes in yield might have considerable impact on the process economics, this adjustment was made to ensure comparability given the uncertainty of different operation modes (batch vs. continuous), substrates (corn stover vs. pure cellulose), resources for enzyme-production (in-situ vs. ex-situ) and maturity levels of 
the technologies. The ethanol rectification, dehydration and storage do not underly appreciable changes. However, due to the considerably reduced salt concentration in the fermentation slurry as result of the changed pretreatment technique, a much larger fraction of the residues can be sent to combustion. This causes a net increase of CAPEX, since the increased CAPEX of an up-scaled combustor overcompensates the reduced CAPEX for a smaller wastewater treatment unit and the saved CAPEX because flue gas desulfurization (FGD) may be omitted. The larger combustion unit produces a higher amount of excess electricity, which generates by-product revenues by selling it to the grid. These extra by-product revenues cause substantial OPEX savings compared to the base case.

To conclude, the CAPEX for a cellulosic ethanol production facility based on CBP increase by $4.77 \%$ despite considerable savings by removing the enzyme production unit (A 400) completely (Fig. 2). The increase is mainly caused by the high apparatus costs for the larger combustor and boiler and the additional evaporators in the purification unit for the separation of process water and the solid residues after fermentation (A 500). Applying the base case financing parameters (plant lifetime, equity share, interest rates on equity and debts, etc.), a capital recovery charge of $25.17 \mathrm{C} /$ annual $\mathrm{L}$ ethanol over the lifetime of the plant instead of $24.02 \mathbb{C}$ /annual $\mathrm{L}$ ethanol is obtained. The total variable OPEX per annual $\mathrm{L}$ ethanol for $\mathrm{CBP}$ amount to $13.86 \mathrm{C} /$ annual $\mathrm{L}$ ethanol instead of $28.46 \mathbb{C}$ /annual $\mathrm{L}$ ethanol in the base case, which corresponds to a reduction of $51.4 \%$ (Fig. 2). $57.0 \%$ of the OPEX savings result from the change in pretreatment (less use of chemicals and better valorization of the residuals due to lower salt concentrations) and $43 \%$ come from applying CBP (omitting the need for glucose supply for enzyme production). The fixed OPEX are slightly reduced to 1.78 \$/annual L ethanol, which corresponds to a reduction of $12.5 \%$ (Fig. 2). The CAPEX-related fixed OPEX (e.g. insurance and maintenance) increase proportionally with the CAPEX, whereas labor costs are saved due the reduced number of process steps.

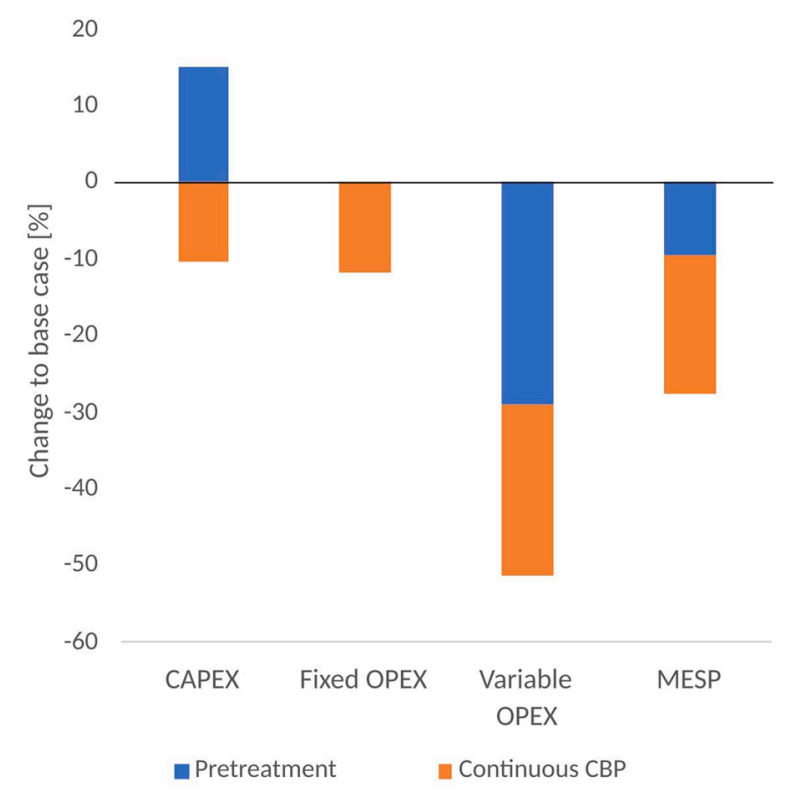

Fig. 2. Relative cost savings of consortium-based CBP compared to the base case for CAPEX, fixed and variable OPEX and the resulting MESP. CBP leads to savings in CAPEX, fixed and variable OPEX. The change in pretreatment increases the CAPEX but reduces the variable OPEX. The fixed OPEX are almost not affected by the pretreatment. The resulting MESP is reduced by $27.5 \%$ compared to the base case due to the change in pretreatment and implementation of consortium-based CBP.
The resulting MESP can be reduced from $56.80 \mathbb{C} /$ annual L ethanol to $41.22 \mathbb{C} /$ annual L ethanol (reduction of $27.5 \%$ ) (Fig. 3). According to CME Group (Chicago, US), one of the largest option exchange companies in the world, the average ethanol price in 2007 was $52.30 \mathrm{C} / \mathrm{L}$ ethanol showing an attractive producer surplus in the case of consortium-based $\mathrm{CBP}$, whereas the base case is not profitable under the given conditions [36].

\section{Sensitivity analysis of the cost savings through consortium-based CBP}

In contrast to 2007, in 2019 the US MESP, including the cost savings achieved by CBP, was with $41.60 \mathbb{\$}$ /annual $\mathrm{L}$ ethanol higher than the average US price of ethanol, which amounted to only $36.75 \mathrm{C} / \mathrm{L}$ ethanol [36]. Despite fluctuations, the US ethanol price has decreased since 2007 on average by $3.9 \%$ per year, while the costs for chemical plants, represented by the CEPCI, have increased by $16.0 \%$ over the same period (Fig. 4) [36].

CBP per se does not enable profitable bioethanol production from lignocellulose in the US nowadays. A sensitivity analysis of the MESP for several process parameters (scale, titer, yield, residence time) and investment parameters (feedstock price, price level in the country of the plant location, costs of capital) was conducted to investigate (a) necessary improvements of the process from an engineering point of view and (b) investment conditions, which allow profitable bioethanol production while still being interesting for shareholders (Fig. 5). In contrast to the base case, the total costs of the CBP scenario are dominated by the CAPEX ( $58 \%$ vs. $42 \%$ of MESP) as a result of the significant reduction of the variable OPEX ( $32 \%$ vs. $50 \%$ of MESP) (see Fig. 3) by CBP. Thus, process/investment parameters affecting the CAPEX tend to be more relevant.

The MESP increases exponentially with a reduction in throughput (Fig. 5a), implying that the MESP is almost inelastic with varying scale above 50 and up to $120 \%$ of the base case scale. For plants with a size below $10 \%$ of the base case, the total costs tend to remain constant independent of the throughput. To calculate the MESP at different production scales, CAPEX and fixed OPEX were scaled with the weighted size exponent (see Supplementary Material A), whereas the variable OPEX per L ethanol were kept constant. For scales below $10 \%$ of the base case (i.e. $<200$ dry tons feedstock per day), a simple scaling with a size exponent was no longer applicable, since significant design adjustments to the process were economically favorable and/or technically necessary, such as omitting the combustion unit in order to operate the wastewater treatment at reasonable scales. A detailed listing of the design adjustments can be found in Supplementary Material A and C. Given these calculations of the MESP at different scales, the exponential dependence is caused by the scaling of the CAPEX with the weighted size exponent. Since its overall value for the whole plant (between $10 \%$ and $120 \%$ of the base case scale) is 0.63 (see Supplementary Material A and C), which is considerably lower than 1 , strong economies of scale effects yield a high MESP sensitivity at lower scales. The economies of scale, and thus the MESP sensitivity, are further increased by synergies, such as production of process steam and electricity revenues due to lignin valorization as well as utilities, common facilities etc. working to capacity, which minimizes the specific costs at large scales. Above $50 \%$ of the base case scale, i.e. 1000 dry $\mathrm{t} /$ day, the economies of scale including all synergies seem to be fully exploited causing the low sensitivity. Below $10 \%$ of the base case scale, economies of scale cannot be exploited further, resulting in almost constant equipment costs resulting in the tremendous increase of the MESP. The discontinuities in the curve below $10 \%$ result from the necessary adaptation of the process layout mentioned above. Additionally, but less important, scale positively affects the variable OPEX, since the relative transport costs for the feedstock increase (see Supplementary Material A). It is not possible to match the ethanol US market price by only varying the scale of the plant.

The MESP also decreases exponentially with the obtained titer (see calculations in Supplementary Material A). The curvature is less 


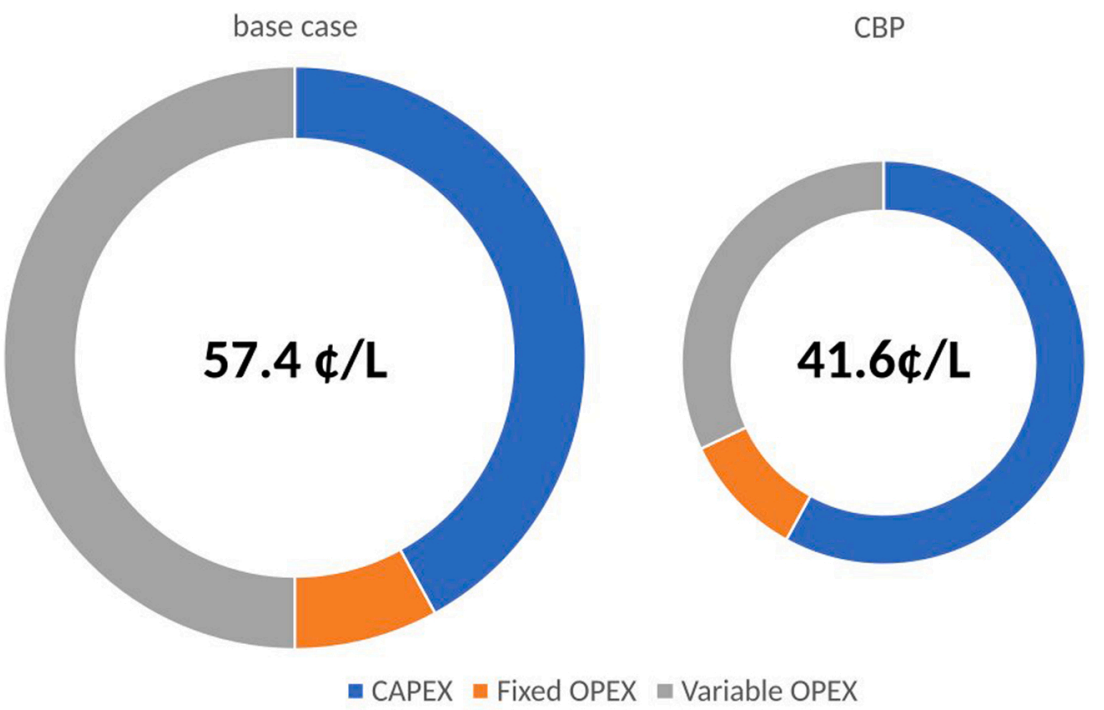

Fig. 3. Share of CAPEX, fixed and variable OPEX of the MESP for the base case and the CBP scenario.

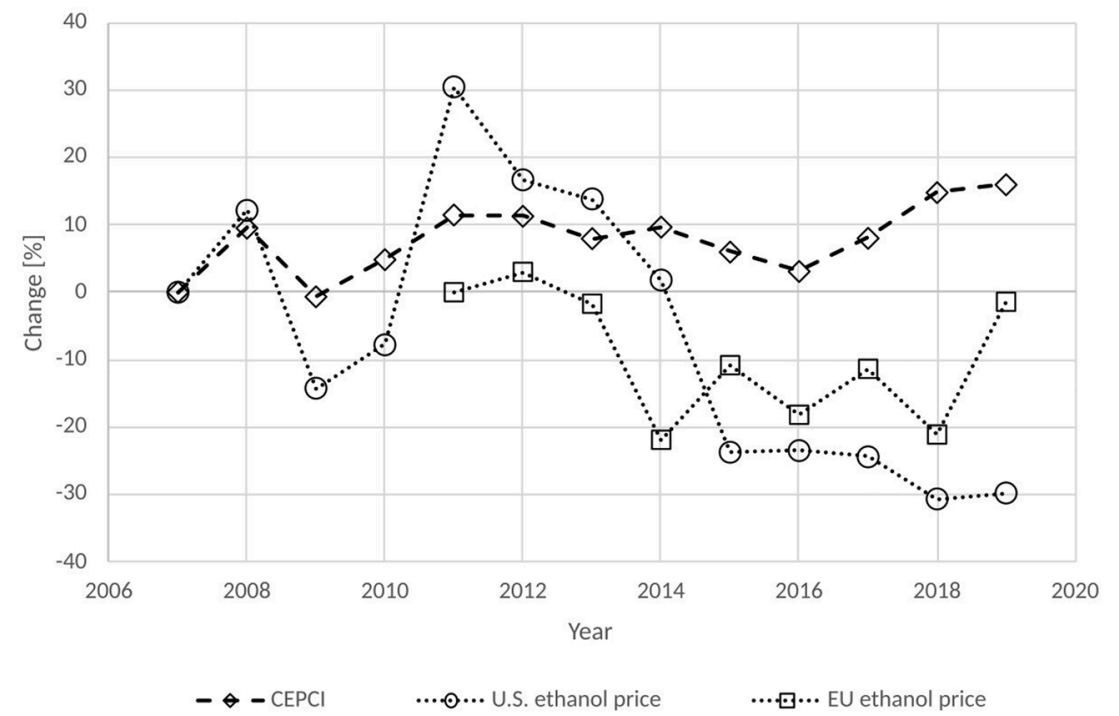

Fig. 4. Development of the ethanol prices in the US and the EU compared to the costs for chemical plants represented by the CEPCI. From 2007 to 2019 , the US ethanol price decreased by $30 \%$ [36], whereas the costs for chemical plants increased by $16 \%$. For the EU ethanol price (domestic ethanol, FoB Rotterdam), data is available from 2011 to 2019 [41]. After a few years with lower price, the price level in 2019 stabilized around the same level as between 2011 and 2013.

remarkable than with throughput, but leading to high MESP sensitivities below 3 wt.\% titer and almost inelastic MESP behavior above 4 wt.\% (Fig. 5b). Thus, the calculations confirm literature stating that a minimum titer of 3-4 wt.\% marks a threshold for any biofuel production process using distillation as part of the product purification [37]. The strong curvature results from the fact that distillation processes are rather inefficient from an exergetic point of view. The number of stages remains almost constant over varying titer (between 0.5 and $10 \mathrm{~g} / \mathrm{L}$ ) (cf. McCabe-Thiele diagram for ethanol water mixtures), but the reflux ratio and thus the energy demand of the rectification column strongly increases at low concentrations [38,39]. The final concentration offers no possibility of approaching the US ethanol market price.

The parameters of residence time, feedstock price, purchasing power parity (PPP) and the capital charge rate are all positively and linearly related to the MESP, while yield is negatively correlated. However, the different parameter sensitivity curves show vast differences in the constant of proportionality (Fig. $5 \mathrm{c}-\mathrm{g}$ ). The residence time has by far the lowest proportionality factor (see calculations in Supplementary Material A), causing $+4 /-2 \%$ MESP by doubling/halving the residence time (Fig. 5d). The residence time affects only the CAPEX share of the hydrolysis and fermentation unit A 300, which is rather irrelevant due to the CBP savings.

The yield influences the MESP considerably more strongly (Fig. 5c): a $10 \%$ difference in yield changes the MESP by around $5 \mathbb{C} / \mathrm{L}$ ethanol (see calculations in Supplementary material A). Higher yields cause a lower MESP due to lower feedstock costs since an increased yield would save a 

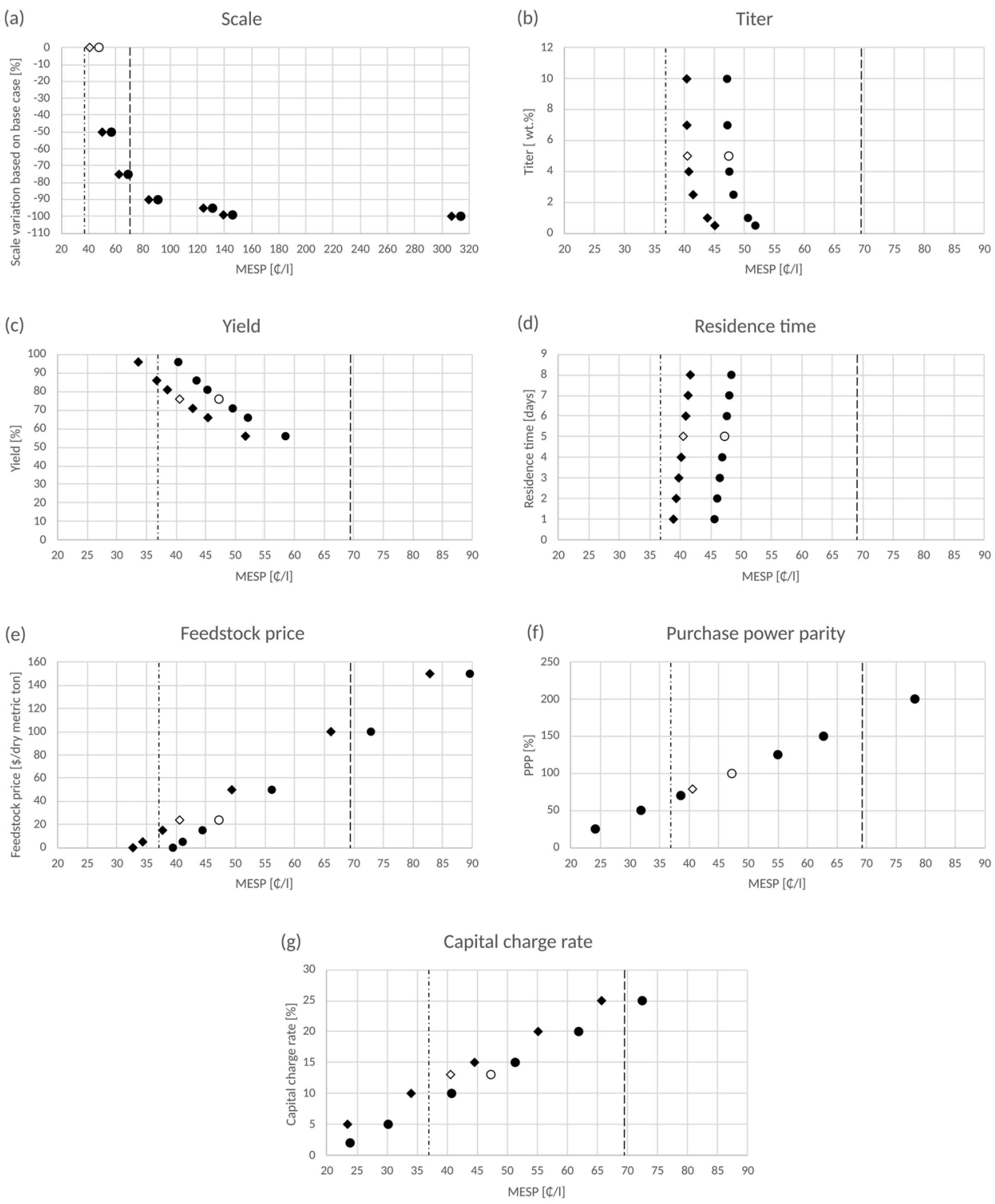

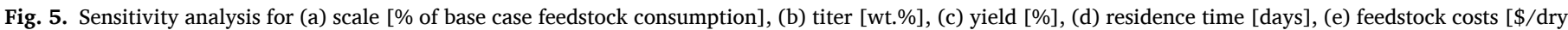

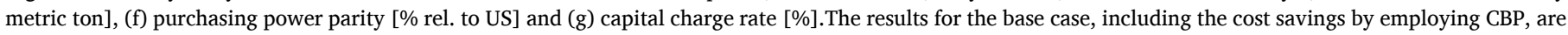

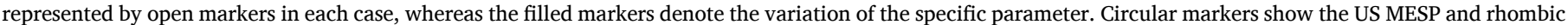

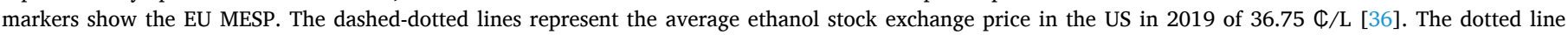
represents the 2019 EU ethanol price (T2 FOB Rotterdam) [41].

certain amount of feedstock per unit product. From a mathematical point of view, this leads to the same result as if the original feed stock amount was purchased at a lower price per feedstock unit (neglecting very minor changes to the apparatus). Since the feedstock price has a significant influence on the MESP (ca. $30 \%$ ), the yield is also relevant. However, despite its significant impact, yield improvements do not lead to profitable production in the US since the yield is already at a high level (76\%).

Feedstock price, PPP and capital charge rate have a comparable, positively correlated, linear influence on the MESP, since they cause a MESP variation width of ca. $55 \mathrm{C} / \mathrm{L}$ ethanol in the observed range (Fig. 5e-g). Since neither the feedstock price, nor the PPP or the capital charge rate affect the sizing of specific apparatus, no size exponent is used and the MESP sensitivity towards these parameters appears linear. The feedstock price has a direct impact on the raw materials' share of the variable OPEX. The PPP is used as an indicator to compare price levels in different countries by denoting the costs of a defined basket of representative goods in a specific country. The PPP of the US is chosen as reference and set to $100 \%$ [38]. It only affects all costs associated with work and with variable OPEX, since a large fraction of the variable OPEX consists of locally traded raw materials such as the feedstock amongst others. The capital charge rate is the return required on invested capital. It is defined by the interest rate on debt capital and the return on equity, as well as the fraction of debt capital and equity, and thus affects the total CAPEX instead of single apparatus/units. Only variations of the PPP and the capital charge rate allow the US market price of ethanol to be met, whereas scale, yield and feedstock price only approach close to the market price. Varying titer and residence time does not allow the market price to be approached substantially.

In contrast to the US, the situation in the EU appears to be much less 
restricted. The lower PPP in the EU (78 \% of the US currency-adjusted [40]) yields an MESP reduction of $6.75 \mathbb{C} / \mathrm{L}$ ethanol (see open rhombic marker in Fig. 5f). Furthermore, ethanol T2 (i.e. of domestic European origin) FOB Rotterdam, NL, has a market price of $69.40 \mathrm{C} / \mathrm{L}$ ethanol (dashed lines in Fig. 5) [41]. Thus, the CBP base case is profitable in the EU (see open rhombic markers in Fig. 5). This allows either to decrease the size of the plant to $15 \%$ of the base case size offering the possibility to valorize local biomass decentrally, or it gives margin to imperfect process conditions or fluctuations of the feedstock price (see filled rhombic markers and dashed lines in Fig. 5). With CBP at base case conditions, up to $30 \%$ total return to shareholders (TRS) may be expected (Fig. $5 \mathrm{f}$ ) meaning that applying CBP offers the potential to outperform the average TRS (24.0\%) of the chemical industry [42].

However, recalling that US ethanol demand is ten times higher than that in the EU [9], it is worth showing profitable scenarios for the US with its much more competitive market environment. Under the given conditions, the only possible approaches to reduce the MESP to the US market price are (i) receiving the feedstock at negative costs (e.g. by utilizing waste feedstocks), (ii) to develop a business plan with much lower return on equity (assuming, that interest rates on debt stay constant), or (iii) production in a country with a lower price level. Considering a shift to waste feedstocks (e.g. solid manure), which could be obtained for free or at negative prices, it might be challenging to maintain the total costs and the amount of annually produced ethanol (e. g. due to abrasive wear as consequence of the high sand loading, which is not yet investigated). In case the use of corn stover as feedstock is required, price levels, which are low enough for the MESP to meet the stock exchange price, may be found in China, Ukraine, India, Indonesia and Russia among the largest corn producing countries [40,43], However, outsourcing second generation bioethanol production to countries with low price levels appears to be a missed opportunity both for exploiting valuable biomass potential in the US and stimulating the economy in their rural areas.

Other options for a profitable process include increasing the local ethanol price at the production site to levels above the world stock exchange price (e.g. due to tariff barriers or if regional production has a market value) or benefiting from an added-value through sustainable production. Alternatively, lower costs of capital or fiscal incentives such as $\mathrm{CO}_{2}$ taxes/compensations or fuel tax exemptions for bioethanol may also enable profitable production.

\section{Comparison of cost savings with GMO-based CBP}

Another economic study using GMO-based CBP for bioethanol production [19] reports $41 \%$ cost savings, which are considerably higher than those of $19 \%$ coming from to the use of consortium-based CBP presented in this work. Slightly different input parameters were used in [17] compared to the NREL base case and this scenario, i.e. costs of capital, scale, titer, yield and residence time and the pretreatment method.

In order to compare savings between GMO-based CBP and consortium-based CBP, the process conditions were levelled to base case conditions (Supplementary Material B). By these adjustments, cost savings of around $20 \%$ result for both variants of CBP, which can be considered identical given the uncertainty $(+/-30 \%)$ of such early-stage cost estimations [44]. Thus, this work supports the conclusion that CBP is the strongest lever to reduce the costs of ethanol production from lignocellulose from a process point of view [19]. Cost savings in the production of cellulosic ethanol are urgently needed given the fact that several full-scale plants are currently either shut down or do not operate at full capacity because of profitability issues amongst others [45-48].

\section{Conclusions}

The presented calculations have shown that consortium-based CBP with steam pretreatment can save up to $27.5 \%$ of the total costs compared to conventional bioethanol production from lignocellulose, which is in the same range as published data on GMO-based CBP. However, even though CBP accounts for the strongest lever to reduce processing costs, per se it does not enable a competitive lignocellulosic ethanol production today. In the EU, the high ethanol market price combined with the low production costs when applying CBP offers a sufficient margin for profitable production or the possibility to decrease the plant size to $15 \%$ and thus decentralize the biomass valorization. However, in the US where $56.2 \%$ of the world's ethanol is currently consumed, the ethanol market is much more competitive. From 2007-2019, the ethanol price dropped by $31 \%$ while the average CAPEX increased by $16 \%$, resulting in a strong competitive pressure for lignocellulosic bioethanol. A cost sensitivity analysis of several process parameters (scale, titer, yield and residence time) and investment parameters (feedstock price, price level in the country of the plant location and costs of capital) show that scale and yield are the main cost-pushers from a process point of view, whereas the price level of the plant location has the highest impact on the investment conditions. Since outsourcing second generation bioethanol production to third world countries with low price levels leaves valuable biomass potential unused and hinders economic growth in rural areas, it should be aimed at meeting the current ethanol market price by taking advantage of the cost levers of multiple process and/or investment parameters if necessary, such as utilizing cheaper waste feedstocks at comparable yields and reducing the costs of capital by accepting lower returns on equity. Alternatively, exploiting the added-value through sustainable production as well as local market disparities such as tariff barriers or tax exemptions may lead to profitable production of lignocellulosic bioethanol. In the short term, retrofitting of depreciated existing corn ethanol plants to CBP operation, might be an interesting approach to reduce the CAPEX in order to meet the world market price of ethanol with lignocellulosic ethanol.

\section{Declaration of Competing Interest}

The authors report no declarations of interest.

\section{Acknowledgements}

This work was supported by the Swiss Confederation through the Swiss Innovation Agency Innosuisse in the framework of the SCCER BIOSWEET (contract umber 1155002550).

\section{Appendix A. Supplementary data}

Supplementary material related to this article can be found, in the online version, at doi:https://doi.org/10.1016/j.nbt.2021.07.005.

\section{References}

[1] U.S. Energy Information Administration. International energy outlook 2020 (IEO2020) [July 19, 2021] Available from:. 2020. https://www.eia.gov/outlooks/ ieo/pdf/ieo2020.pdf.

[2] Conti J, Holtberg P, Diefenderfer J, LaRose A, Turnure JT, Westfall L. International energy outlook 2016 with projections to 2040. 2016. https://doi.org/10.2172/ 1296780.

[3] Fulton LM, Lynd LR, Körner A, Greene N, Tonachel LR. The need for biofuels as part of a low carbon energy future. Biofuels Bioprod Bioref 2015;9(5):476-83. https://doi.org/10.1002/bbb.1559.

[4] U.S. Energy Information Administration. International Energy outlook 2019: with projections to 2050. Washington, DC [March 4, 2021] Available from:. 2019. https://www.eia.gov/outlooks/ieo/pdf/ieo2019.pdf.

[5] Organisation for Economic Co-operation and Development. Energy technology perspectives 2016: towards sustainable urban energy systems. Paris, France: International Energy Agency; 2016.

[6] IEA P. Energy technology perspectives 2012: pathways to a clean energy system [March 4, 2021] Available from: International Energy Agency Paris; 2012. http s://www.iea.org/reports/energy-technology-perspectives-2012.

[7] van Haveren J, Scott EL, Sanders J. Bulk chemicals from biomass. Biofuels Bioprod Bioref 2008;2(1):41-57. https://doi.org/10.1002/bbb.43. 
[8] Zabed H, Sahu JN, Suely A, Boyce AN, Faruq G. Bioethanol production from renewable sources: current perspectives and technological progress. Renewable Sustain Energy Rev 2017;71:475-501. https://doi.org/10.1016/j. rser.2016.12.076.

[9] OECD-FAO. Agricultural outlook 2019-2028 [March 4, 2021] Available from: OECD; 2019. https://www.oecd-ilibrary.org/agriculture-and-food/oecd-fao-a gricultural-outlook-2019-2028_agr_outlook-2019-en.

[10] Fargione J, Hill J, Tilman D, Polasky S, Hawthorne P. Land clearing and the biofuel carbon debt. Science 2008;319(5867):1235-8. https://doi.org/10.1126/ science. 1152747.

[11] Brethauer S, Studer MH. Biochemical conversion processes of lignocellulosic biomass to fuels and chemicals - a review. Chimia (Aarau) 2015;69(10):572-81. https://doi.org/10.2533/chimia.2015.572.

[12] Ricardo Soccol C, Faraco V, Karp S, Vandenberghe LP, Thomaz-Soccol V, Woiciechowski A, et al. Lignocellulosic bioethanol. Biofuels. Elsevier; 2011. p. 101-22. https://doi.org/10.1016/B978-0-12-385099-7.00005-X.

[13] Arevalo-Gallegos A, Ahmad Z, Asgher M, Parra-Saldivar R, Iqbal HMN. Lignocellulose: a sustainable material to produce value-added products with a zero waste approach-a review. Int J Biol Macromol 2017;99:308-18. https://doi.org/ 10.1016/j.ijbiomac.2017.02.097.

[14] Alternative Fuels Data Center. Second generation biofuel producer tax credit [July 19, 2021]; Available from:. 2021. https://afdc.energy.gov/laws/10515.

[15] Pu Y, Zhang D, Singh PM, Ragauskas AJ. The new forestry biofuels sector. Biofuels Bioprod Bioref 2008;2(1):58-73. https://doi.org/10.1002/bbb.48.

[16] da Costa Sousa L, Chundawat SPS, Balan V, Dale BE. 'Cradle-to-grave' assessment of existing lignocellulose pretreatment technologies. Curr Opin Biotechnol 2009;20 (3):339-47. https://doi.org/10.1016/j.copbio.2009.05.003.

[17] Shahab RL, Luterbacher JS, Brethauer S, Studer MH. Consolidated bioprocessing of lignocellulosic biomass to lactic acid by a synthetic fungal-bacterial consortium. Biotechnol Bioeng 2018;115(5):1207-15. https://doi.org/10.1002/bit.26541.

[18] Lynd LR, Liang X, Biddy MJ, Allee A, Cai H, Foust T, et al. Cellulosic ethanol: status and innovation. Curr Opin Biotechnol 2017;45:202-11. https://doi.org/10.1016/j. copbio.2017.03.008.

[19] Lynd LR, Laser MS, Bransby D, Dale BE, Davison B, Hamilton R, et al. How biotech can transform biofuels. Nat Biotechnol 2008;26(2):169-72. https://doi.org/ 10.1038/nbt0208-169.

[20] Stankiewicz AI, Moulijn JA. Process intensification: transforming chemical engineering. Chem Eng Prog 2000;96(1):22-34 [March 4, 2021] Available from: https://www.aiche.org/sites/default/files/docs/news/010022_cep_stankiewicz.pd f.

[21] Minty JJ, Singer ME, Scholz SA, Bae C-H, Ahn J-H, Foster CE, et al. Design and characterization of synthetic fungal-bacterial consortia for direct production of isobutanol from cellulosic biomass. Proc Natl Acad Sci U S A 2013;110(36): 14592-7. https://doi.org/10.1073/pnas.1218447110.

[22] Shahab RL, Brethauer S, Davey MP, Smith AG, Vignolini S, Luterbacher JS, et al. A heterogeneous microbial consortium producing short-chain fatty acids from lignocellulose. Science 2020;369(6507). https://doi.org/10.1126/science. abb1214.

[23] Brethauer S, Shahab RL, Studer MH. Impacts of biofilms on the conversion of cellulose. Appl Microbiol Biotechnol 2020;104(12):5201-12. https://doi.org/ 10.1007/s00253-020-10595-y.

[24] Brethauer S, Studer MH. Consolidated bioprocessing of lignocellulose by a microbial consortium. Energy Environ Sci 2014;7(4):1446. https://doi.org/ 10.1039/c3ee41753k.

[25] Shahab RL, Brethauer S, Luterbacher JS, Studer MH. Engineering of ecological niches to create stable artificial consortia for complex biotransformations. Curr Opin Biotechnol 2020;62:129-36. https://doi.org/10.1016/j.copbio.2019.09.008.

[26] Roell GW, Zha J, Carr RR, Koffas MA, Fong SS, Tang YJ. Engineering microbial consortia by division of labor. Microb Cell Fact 2019;18(1):35. https://doi.org/ 10.1186/s12934-019-1083-3.

[27] Peng X, Gilmore SP, O'Malley MA. Microbial communities for bioprocessing: lessons learned from nature. Curr Opin Chem Eng 2016;14:103-9. https://doi.org/ 10.1016/j.coche.2016.09.003.

[28] Humbird D, Davis R, Tao L, Kinchin C, Hsu D, Aden A, et al. Process design and economics for biochemical conversion of lignocellulosic biomass to ethanol: diluteacid pretreatment and enzymatic hydrolysis of corn stover. 2011. https://doi.org/ 10.2172/1013269.

[29] Shahab RL. Labor division in engineered cross-kingdom consortia: consolidated bioprocessing of lignocellulosic biomass to carboxylic acids [March 4, 2021] Available from: Lausanne: EPFL; 2021. https://infoscience.epfl.ch/record/2652 80/files/.

[30] Brethauer S, Antczak A, Balan R, Zielenkiewicz T, Studer MH. Steam explosion pretreatment of beechwood. Part 2: quantification of cellulase inhibitors and their effect on avicel hydrolysis. Energies 2020;13(14):3638. https://doi.org/10.3390/ en13143638.

[31] Kadam KL, Rydholm EC, McMillan JD. Development and validation of a kinetic model for enzymatic saccharification of lignocellulosic biomass. Biotechnol Prog 2004;20(3):698-705. https://doi.org/10.1021/bp034316x.

[32] Turton R. Analysis, synthesis, and design of chemical processes [March 4, 2021] Available from:. 5th ed. Boston: Prentice Hall; 2018. https://www.pearson.ch/Info rmatik/PrenticeHall/EAN/9780132618120/Analysis-Synthesis-and-Design-of-Che mical-Processes.

[33] Ulrich GD, Vasudevan PT. Chemical engineering process design and economics: practical guide [March 4, 2021] Available from:. 2nd ed. Durham N.H.: Process Pub; 2004. https://www.xanedu.com/higher-education/educators/custom-bookscatalog/chemical-engineering/.
[34] Garrett DE. Chemical engineering economics [March 4, 2021] Available from: Springer Science \& Business Media; 2012. https://www.springer.com/gp/book/9 789401165464.

[35] Aden A, Ruth M, Ibsen K, Jechura J, Neeves K, Sheehan J, et al. Lignocellulosic biomass to ethanol process design and economics utilizing co-current dilute acid prehydrolysis and enzymatic hydrolysis for corn stover. 2002. https://doi.org/ 10.2172/15001119.

[36] Ethanol futures historical prices - Investing.com. 2019 [August 14, 2019]; Available from: https://www.investing.com/commodities/ethanol-futures-histor ical-data.

[37] Vane LM. Separation technologies for the recovery and dehydration of alcohols from fermentation broths. Biofuels Bioprod Bioref 2008;2(6):553-88. https://doi. org/10.1002/bbb.108.

[38] Kiss AA. Design, control and economics of distillation. In: Kiss AA, editor. Advanced distillation technologies. Chichester, UK: John Wiley \& Sons, Ltd; 2013. p. 37-65. https://doi.org/10.1002/9781118543702.

[39] Haelssig JB, Tremblay AY, Thibault J. Technical and economic considerations for various recovery schemes in ethanol production by fermentation. Ind Eng Chem Res 2008;47(16):6185-91. https://doi.org/10.1021/ie0715005.

[40] Conversion rates - Purchasing power parities (PPP) - OECD Data. 2019 [August 16, 2019]; Available from: https://data.oecd.org/conversion/purchasing-powe r-parities-ppp.htm.

[41] Biofuelscan S\&P global platts. 2020 [November 11, 2020]; Available from: https:// www.spglobal.com/platts/en/products-services/agriculture/biofuelscan.

[42] Ezekoye O, Milutinovic A, Simons TJ. Chemicals and capital markets: back at the top. McKinsey \& Company; 2018. 10 May 2018; Available from: https://www. mckinsey.com/industries/chemicals/our-insights/chemicals-and-capital-marketsback-at-the-top. [October 06, 2020].

[43] FAOSTAT. [August 16, 2019]; Available from: http://www.fao. org/faostat/en/\#data/QC.

[44] Tsagkari M, Couturier J-L, Kokossis A, Dubois J-L. Early-stage capital cost estimation of biorefinery processes: a comparative study of heuristic techniques. ChemSusChem 2016;9(17):2284-97. https://doi.org/10.1002/cssc.201600309.

[45] Abengoa sells Hugoton cellulosic ethanol plant for Synata Bio. The Wichita Eagle. 2019 [August 15, 2019]; Available from: https://www.kansas.com/news/b usiness/article119902263.html.

[46] Assets of former Ineos Bio plant to be sold piecemeal via auction. 2019 Biomassmagazine.com. [August 15, 2019]; Available from: http://biomassmagazi ne.com/articles/15871/assets-of-former-ineos-bio-plant-to-be-sold-piecemealvia-auction.

[47] DuPont seeks to sell cellulosic ethanol plant. Chemical \& engineering news. 2019 [August 15, 2019]; Available from: https://cen.acs.org/articles/95/web/2017/11/ DuPont-seeks-sell-cellulosic-ethanol.html.

[48] Ethanol producer magazine - the latest news and data about ethanol production. 2019 [August 15, 2019]; Available from: http://www.ethanolproducer.com/artic les/15344/zero-to-10-million-in-5-years.

\section{Glossary}

Bio-based economy: An economy model, where the production of all goods and services, which contribute to the economy, is based on sustainable use of renewable resources. Capital charge rate: The capital charge rate [\%] determines the fraction of the invested capital, which is required annually to satisfy interests on debt and equity.

Carbon debt: The difference between the emitted $\mathrm{CO}_{2}$ of a certain system (e.g. emissions of land clearing measures to cultivate crop) and the resorbed $\mathrm{CO}_{2}$ of the system (e.g. by crop growth).

Carbon footprint: Total $\mathrm{CO}_{2}$ emission of a certain system over its lifecycle.

Chemical Engineering Plant Cost Index: An index representing the development of equipment, construction labor, buildings as well as engineering and supervision over time in order to compare costs of different years.

Consolidated bioprocessing: The highest degree of process integration in bioprocesses, where enzyme production, substrate hydrolysis and fermentation to the final product is carried out in a single process step.

Energy efficiency: The energy efficiency [\%] determines the fraction of energy bound in the feedstock, which is conserved in the products of the bioprocess.

Enzymatic hydrolysis: Enzymatic hydrolysis describes the depolymerization of cellulose to sugars catalyzed by a specific cocktail of enzymes.

Installation factor: The multiplication of the installation factor with the apparatus costs of a certain process step gives an estimate for the installed costs. It reflects the costs for piping, armatures etc.

Market disparity: Market disparities describe the situation, when a good's or a service's price deviates from the market price.

Purchasing power parity: The purchasing power parity is an index to determine the price level of a certain country by comparing the costs of a defined basket of goods in this country with other countries.

Tariff barrier: Tariff barriers are taxes imposed upon imports in order to make them more expensive than comparable goods of domestic production.

Titer: The titer corresponds to the concentration of the final good.

Total return to shareholders: The total return to shareholders summarizes all capital gains and dividends, which an investor receives from the investment.

Size exponent: The size exponent of a certain apparatus links the size of this apparatus with its costs and thus, the size exponents determines the economies of scale of this apparatus. 